\title{
GENETIC MANIPULATIONS IN AUTO-INDUCED PROTOPLASTS OF BACILLUS THURINGIENSIS
}

\author{
CLARA P. RUBINSTEIN \& CARMEN SANCHEZ-RIVAS
}

Institu to de Investigaciones en Ingeniería Genética y Biología Molecular (INGEBI-CONICET), Vuelta de Obligado 2490 (1428) Buenos Aires, Argentina

Bacillus thuringiensis, constitutes the most studied group of spore-forming bacilli for their application to the biological control of insects. In particular, the subspecies israelensis (Bti) is being used in the control of Dipteran vectors in several tropical areas affected by endemic parasitic diseases (Margalit \& Dean, 1985).

The larvicidal activity of these bacilli resides in the parasporal inclusion, which synthesis is strictly coupled to the sporulation process. This inclusion consists of three different types of sub-inclusions, probably contributing to the high toxicity of intact cristals in a synergistic manner, as has been proposed by different authors (Ibarra \& Federici, 1986; Wu \& Chang, 1986).

Several laboratories have undertaken the molecular cloning of Bti toxin genes, which are all carried on a $110 \mathrm{~kb}$ resident megaplasmid. These studies have led to the identification of at least three genes responsible for the synthesis of the three major polipeptides observed by SDS/PAGE (130, 65 and $28 \mathrm{kd}$ ) (Thorne et al., 1986; Bourgouin et al., 1986; Ward \& Ellar, 1988).

It is now clear that synthesis and assemblage of fully toxic parasporal crystals is subjected to complex regulatory mechanisms in the natural host strains of $B$. thuringiensis. In this sense, the role of certain resident plasmids (in particular low molecular weight ones) might be of special importance to these mechanisms.

Therefore, it would be desirable to undertake the reintroduction of manipulated genes back into the parental strains, since this would be the most appropriate genetic and physiological background for the expression and regulation of these genes. This type of genetic manipulation, would not only be of great interest for the study of the basic regulatory mechanisms involved, but also in the construction of im- proved strains with higher levels of toxins, multispecific, with higher residual activities, etc.

One of the major obstacles to this approach, however, is the lack of available efficient transformation techniques. In this sense, several laboratories have reported transformation protocols with varied results. In general, the transformation of protoplasts was the approach, since it has not been possible to induce a competent state in these bacilli. Nevertheless, the production of protoplasts as well as the transformation efficiencies obtained were generally low and strongly dependent on the strains studied (Martin et al., 1981; Miteva et al., 1981; Crawford et al., 1987; Heierson et al., 1987).

In our laboratory, a highly efficient method for the conversion to protoplasts was achieved for several subspecies of $B$. thuringiensis. The protoplastization process occurs in the absence of hydrolitic enzymes and would involve the induction or activation of endogenous autolytic factors under specific growth conditions (Rubinstein \& Sanchez-Rivas, 1988; Aronson et al., 1986; Temeyer, 1987).

The protoplastization efficiencies obtained range between $99.6 \%$ for subspecies thuringiensis and $100 \%$ for israelensis. The process, involves extrusion of the protoplasts through "holes" produced on the cell wall by the autolytic activities; in this way, protoplasts completely devoid of cell wall are generated. This fact, has important consequences on the ulterior regeneration processes, due to the lack of sufficient wall primers on the surface of these protoplasts.

PEG - Mediated Transformation - We have also carried out transformation experiments with Bti protoplasts, utilizing a modified version of the Chang \& Cohen method developed for $B$. subtilis. 
Transformation efficiencies ranged between 1 and 3 percent of the regenerant cells for plasmids pT127 (tetracyclin resistance) and pTV1 (chloromphenicol and erythromycin) respectively. Although these efficiencies are very high among the regenerants, the overall recovery of transformants per microgram of plasmid DNA is low (around $10^{3}$ and $10^{4}$ ), due to the low level of regeneration achieved in solid media.

On the other hand, liquid regeneration is completely achieved after incubation of the protoplasts in a protected rich medium at $30{ }^{\circ} \mathrm{C}$ for a ten to twelve hours minimum period. However, this type of regeneration is not desirable when plasmid transformation is performed, due to a high loss of plasmids during the process. In fact, transformation efficiencies fall at least two orders of magnitude with respect to the experiments in which solid regeneration was used. Bti strain 4Q2-72 transformed with plasmid pTV1, rendered $1 \times 10^{-5}$ transformants per viable cell after liquid regen. eration.

Fusion experiments - In view of the high efficiency method we had at hand for the production of stable protoplasts, we applied them to interspecific fusion experiments with B. subtilis.

For this purpose, strain IA510 was chosen, due to its genetic background (recE4, modification-restriction deficient) which would favor the establishment and maintenance of foreign DNA. Fusion was carried out between heatinactivated Bti and IA510 protoplasts using the method of Schaeffer (Schaeffer et al., 1976).

Between 5 and $10 \%$ of the regenerant clones were protothrophic fusion products (IA510 is ley thr arg), indicating a high fusion efficiency. Segregational analysis of these ex-fusants (all bearing $B$. subrilis morphology), revealed a high stability, which indicates a probable recombinational origin (by recE 4 independent mechanisms or recombinogenic capacity provided by $B(i)$ and not a complementation phenomenon.

On the other hand, the transfer of high and low molecular weight plasmids was achieved upon fusion, making this kind of manipulation interesting as an alternative for plasmid transfer.
Conclusion and Perspectives - The high. efficiency method developed for the production of protoplasts in $B$. thuringiensis, allowed us to perform plasmid transformation as well as interspecific fusion experiments. Recovery of transformants among regenerants is high (up to 3\%) considering the low amounts of plasmid DNA used (between 600 and $900 \mathrm{ng}$ ), compared to $5.10 \mu \mathrm{g}$ reported in the literature for this kind of experiment (Crawford et al., 1987; Heierson et al., 1987).

On the other hand, our results show that the chromosomal traits of $B t i$ are able to be expressed in $B$. subtilis and also that plasmid transfer can be achieved in the process.

It is evident that the main obstacle for a more efficient utilization of these protoplasts is their poor regenerative capacity. However, it is our experience that a more efficient regeneration leads to lower recoveries of transformants and/or fusion products.

In conclusion, the use of protoplasts in these strains (generated by this or other methods), involves a compromise between an efficient reversion to the bacillary form and efficient uptake of DNA which depends on a completely exposed cellular membrane.

In the future, the search for alternative transformation protocols should be undertaken, as well as the improvement of the regenerative capacity of these bacilli. This could be probably achieved through the isolation of variants which are able to regenerate on solid media at high levels, or through the construction of strains with this capacity by interspecific fusion. Also, the development of more adequate plasmids to the $B$. thuringiensis genetic context would be advisable.

The development of efficient and reproducible techniques for the genetic manipulation of these bacilli, will make possible a variety of studies regarding the regulation of toxin synthesis, as well as the improvement of the strains currently used in the control of disease vectors.

\section{REFERENCES}

ARONSON, A.; BECKMAN, W. \& DUNN, P., 1986. Bacillus thuringiensis and Related Insect Pathogens. Microbiol. Rev., 50: 1-24.

BOURGOUIN, C.; KLIER, A. \& RAPOPORT, G., 
1986. Characterization of the Genes Encoding the Haemolytic Toxin and the Mosquitocidal DeltaEndotoxin of Bacillus thuringiensis israelensis. MGG, 205: 390-397.

CRAWFORD, I.; GREIS, K.; PARKS, L. \& STREIPS, U., 1987. Facile Autoplast Generation and Transformation in Bacillus thuringiensis israelensis. J. Bacteriol., 169: 5423.5428.

HEIERSON, A.; LANDEN, R.; LEVGREN, A.; DALHAMMAR, G. \& BOMAN, H., 1987. Transformation of Vegetative Cells of Bacillus thuringiensis by Plasmid DNA. J. Bacteriol., 169: 1147-1152.

JBARRA, J. \& FEDERICI, B., 1986. Isolation of A Relatively Non Toxic $65 \mathrm{Kd}$ Protein Inclusion From The Parasporal Body of Bacillus Thuringiensis ismelensis. J. Bacteriol., 165:527-533.

MARGALIT, J. \& DEAN, D., 1985. The Story of Bacillus thuringiensis israelensis. J. Am. Mosq. Control Assoc., 1: 1-7.

MARTIN, P.; LOHR, J. \& DEAN, D., 1981. Transformation of Bacillus thuringiensis Protoplasts by Plasmid DNA. J. Bacteriol, 145:980-983.

MITEVA, V.; SHIVAROVA, N. \& GRIGOROVA, R., 1981. Transformation of Bacillus thuringiensis Protoplasts by Plasmid DNA. FEMS Microbiol. Lett., 12: 253-256.
RUBINSTEIN, C. \& SANCHEZ-RIVAS, C., 1988. Production of Protoplasts by Autolytic Induction in Bacillus thuringiensis: Transformation and Interspecific Fusion. FEMS Microbiol. Lett., 52: 67-72.

SCHAEFFER, P.; CAMI, B. \& HOTCHKISS, R., 1976. Fusion of Bacterial Protoplasts. PNAS USA, 77: 2151-2155.

TEMEYER, K., 1987. Comparison of Methods for Protoplast Formation in Bacillus thuringiensis. J. Gen. Microbiol, 133: 503-506.

THORNE, C.; GARDUNO, F.; THOMPSON, T.; DECKER, N.; ZOUNES, M.; WILD, M.; WALFIELD, A. \& POLLOCK, T., 1986. Structural Similarity Between the Lepidoptera and DipteraSpecific Insecticidal Endotoxin Genes of Bacillus thuringiensis kurstaki and israelensis J. Bacteriol., 166: 801-811.

WARD, S. \& ELLAR, D., 1988. Cloning and Expression of Two Homologous Genes of $B$. thuringiensis israelensis Which Encode $130 \mathrm{Kd}$ Mosquitocidal Proteins. J. Bacteriol, 170: 727-735.

WU, D. \& CHANG, F., 1986. Synergism in Mosquitocidal Activity of $26 \mathrm{Kd}$ and $65 \mathrm{Kd}$ Proteins From Bacillus thuringiensis israelensis. FEBS Lett., 190: 232-236. 